\title{
Margaret McCartney: A sexist contract for junior doctors
}

\author{
Margaret McCartney, general practitioner
}

Glasgow

The Department of Health has published the contract about to be imposed on junior doctors in England, along with a related "equality analysis" and a "family test." 12

Even with an imposed contract, the government has duties under the Equalities Act: UK law forbids direct discrimination against women and disabled people. And the department's self penned analysis concludes that the contract is "fair and justified as good for both staff and patients." But, in the Department of Health's own words, this contract may "disadvantage women working part time."

Indirect discrimination, however-something that puts someone with a protected characteristic at a disadvantage - is lawful "if it is a proportionate means of achieving a legitimate aim." The legitimate aim is, apparently, seven day working. The proportionate means is introducing a model of pay increments that could disadvantage doctors who work part time. By a clear majority, this will mean women.

Women in medicine are no longer the exception: most GPs and junior doctors in the United Kingdom are women. But women have always been intimately involved in delivering NHS services-it's just that they weren't acknowledged or paid for it.

It used to be overwhelmingly women who looked after families and relatives and homes while their partners were operating and doctoring into the evenings and weekends. Typically, women took messages for their GP husbands, tethered to the children and the telephone for weekends and overnights.

When women finally broke through into medical school in decent numbers, working patterns had to change. It was not reasonable to expect anyone to deliver safe patient care in 100 hour working weeks. But it's a curious profession, where 35-40 hours a week counts as part time.
Women's roles of old have been subsumed partly by out-of-hours centres in general practice, but childcare can't be. Crèches that offer overnight care are exceptional. Nannies cost a fortune.

Many grandparents, pension ages now extended, would have been happy to help but will now likely be working themselves. The Department of Health notes that more evening and weekend working for juniors may result in "cheaper and more informal childcare arrangements"- - a statement devoid of knowledge of market forces and with the presumption of a small army of willing and nearby relatives who will step into the unpaid roles that women thought they had long stepped away from.

Having more part time doctors, whether because of health, caring responsibilities, commissioning, or management, will mean that we need more doctors overall. This was predictable decades ago, even before the avoidable mass exodus we're seeing under Jeremy Hunt.

And finally, spectacularly, the deluded department admits, "We envisage that as doctors' awareness of the reality of the content of the new contract increases ... its popularity will increase." So, if you don't like it, ladies, you will simply learn to.

Competing interests: See www.bmj.com/about-bmj/freelancecontributors/margaret-mccartney.

Provenance and peer review: Commissioned; not externally peer reviewed.

1. Department of Health. Equality analysis on the new contract for doctors and dentists in training in the NHS. Mar 2016. www.gov.uk/government/uploads/system/uploads/ attachment_data/file/512696/jd-eia.pdf.

2 Department of Health. Family test for the new contract for doctors and dentists in training in the NHS. Mar 2016. www.gov.uk/government/uploads/system/uploads/attachment_ data/file/512699/jd-family-test.pdf.

Published by the BMJ Publishing Group Limited. For permission to use (where not already granted under a licence) please go to http://group.bmj.com/group/rights-licensing/ permissions 